\title{
Environmental Innovation Impact analysis with the GMR-Europe Model*
}

\begin{abstract}
This study introduces and applies a modelling system that is suitable for the impact assessment of environmental innovations referred to as "Blue Economy" innovations. The paper's contribution to the literature is threefold. First, the building of a multi-sector computable general equilibrium (CGE) model, which provides the theoretical framework for studying the economic impacts of using waste as a production input. Second, the creation of an empirical methodology through which new Blue Economy technologies can be concretely accounted for in regional input-output tables. Since Blue Economy innovations are mostly built on local inputs, their effects are primarily local. Third, given that interregional spillovers of local impacts might also be significant, through interregional trade or migration, a modelling approach that can follow complex spatial processes is applied. The broader model framework chosen is the GMR-Europe model.
\end{abstract}

Keywords: GMR model, Blue Economy, computable general equilibrium models, TFP, innovation.

\section{Introduction}

Compared to traditional, "green" environmentally friendly technologies, Blue Economy innovations require lower costs and offer a positive return in the short term (Pauli 2010). The subtitle of Pauli's book ("10 years, 100 innovations, 100 million jobs"), though it does not lack a marketing trick that is still acceptable in a popular publication, stimulates the economic perspective. Might these innovations indeed have such a significant impact? Besides protecting the environment, are they indeed more effective economically? How can we estimate the economic implications of these innovations more precisely? These questions motivated the modelling approach introduced in this study.

a) Department of Economics and Regional Studies and MTA-PTE Innovation and Economic Growth Research Group Faculty of Business and Economics, University of Pécs, H-7622 Pécs, Rákóczi út 80., Hungary. E-mail: vargaa@ktk.pte.hu

b) MTA-PTE Innovation and Economic Growth Research Group Faculty of Business and Economics, University of Pécs, H-7622 Pécs, Rákóczi út 80., Hungary, E-mail: hau@ktk.pte.hu

c) Department of Economics and Regional Studies Faculty of Business and Economics, University of Pécs, University of Pécs, H-7622 Pécs, Rákóczi út 80., Hungary, E-mail: szabon@ktk.pte.hu

d) MTA-PTE Innovation and Economic Growth Research Group and Department of Economics and Regional Studies Faculty of Business and Economics, University of Pécs , H-7622 Pécs, Rákóczi út 80., Hungary, E-mail: jarosip@ktk.pte.hu

* The research underlying this study was supported by the SROP-4.2.1.B-10/2/KONV-2010-0002 and by the TÁMOP4.2.2.A-11/1/KONV-2012-0058 projects. The contribution by Katalin Erdős is highly appreciated. 
Typical innovations recommended by Pauli (2010) are technological novelties that turn a by-product, usually treated as waste, into the raw material of another economic activity. Perhaps the most popular example is the innovation that produces edible mushrooms on coffee grounds, which is otherwise considered mass-produced waste. Such technologies both mitigate environmental pollution and waste production, and lower the demand for natural resources. Consequently, Blue Economy innovations fundamentally change the relationships among economic sectors, since an unutilized material becomes a raw material for another sector after the introduction of the innovations.

Modelling Blue Economy innovations poses a threefold challenge for the economic analyst. The first challenge is the development of a model framework that can handle the effects of the transformation of waste into a useful material. The second challenge is the representation of new technologies in a way that makes the "translation" of a new technology into the structure of an empirical economic model possible. The third challenge is related to the method of estimating the geographical impacts of an innovation. Although the effect will clearly be stronger in the geographical area where the implementation of the new technology takes place, the spillover effects that indirectly arise in other regions through for example trade or migration need to be recognised. It is also important to measure the magnitude of the impact of Blue Economy innovations on the nation's economy as a whole.

Methodologies available in the literature have only limited relevance for resolving the modelling challenges set by Blue Economy innovations. The first group of models dealing with waste management, specifically recycling, focus only on the determination of the quantity of waste produced, but it lacks an explicit waste management sector (Barata 2002). The second group of models already and explicitly includes waste management and processing. In the three-sector equilibrium model of Miyata (1995), one of the sectors is responsible for processing of waste. Thus the cost of waste management is endogenously determined. Speck (1997) introduces a six-“sector" model where four sectors describe the technologies optionally available for the economy; the fifth sector can be interpreted as waste management that reduces environmental pollution, while the sixth sector includes the waste decomposing capability of nature. The sector in charge of waste management reduces the environmental burden through spending, but the model does not take into consideration the opportunity to utilize waste as a raw material. Different technologies use different mixes of interim products, labour, capital and natural resources. The optimal technology, given the circumstances, is determined by society based on a social welfare function. The disadvantage of this solution is the difficulty related to the appraisal of technologies that change over time.

Though the models described above already endogenously include the cost of waste management, they do not consider recycled waste as a raw material. The problem investigated by Baumgärtner (2004) stands closest to the types of innovations analysed in our study. The author studies recycling of waste paper as a raw material that can be reused in paper production. Waste paper can be valued positively as a secondary resource, but in excess, it is a harmful waste that burdens the environment. This view is strengthened by empirical observations showing that the price of waste paper is positive in some periods while negative in others. To underpin this, Baumgärtner (2004) analyses a two-sector economy where the by-product of one sector is either utilized by another as a raw material 
or must be processed as a waste that induces costs for the company. The cost of waste processing is exogenously given in the model. The author points out that the price of waste paper is negative and equals the cost of waste processing if the waste is not fully utilized. However, Baumgärtner's (2004) solution is one of partial equilibrium, since it does not model the waste-processing sector. The cost of waste processing is exogenously given.

Each of the three types of models introduced in the above categorization play a significant role in our solution. The paper's intention is the development of a model that explicitly enables the utilization of waste as a raw material, similarly to that of Baumgärtner's (2004) solution, but does so in a general equilibrium framework that endogenously includes the price of waste management, as in Miyata's (1995) model.

This study introduces and applies a modelling system that is suitable for the impact assessment of environmental innovations referred to as "Blue Economy" innovations. The paper's contribution to the literature is threefold. First, the building of a multi-sector computable general equilibrium (CGE) model, which provides the theoretical framework for studying the economic impacts of using waste as a production input. Second, the creation of an empirical methodology through which new Blue Economy technologies can be concretely accounted for in regional input-output tables. Since Blue Economy innovations are mostly built on local inputs, their effects are primarily local. Third, given that interregional spillovers of local impacts might also be significant, through interregional trade or migration, a modelling approach that can follow complex spatial processes is applied. The broader model framework chosen is the GMR-Europe model.

The paper is structured as follows. The second chapter introduces the structure of the model. First, the GMR-Europe model is briefly presented, and then the extension of this model is described. Data are presented in the third chapter. This is then followed by a Blue Economy innovation economic impact study. The summary concludes the paper.

\section{The environmental innovation impact analysis model}

\section{The GMR-Europe model}

Quantifying the impacts of Blue Economy innovations was carried out within the framework of the GMR (Geographic Macro and Regional) model. This model can take into consideration the national and regional impacts of different economic interventions. It is frequently used for the impact assessments of interventions targeting $\mathrm{R} \& \mathrm{D}$, human capital, and that of the EU cohesion policy both for the European Union (Varga et al. 2009 and 2013, Varga-Törma 2010), and for Hungary (Varga et al. 2008, Járosi et al. 2010).

The GMR approach is an economic development policy impact-modelling framework. GMR models provide ex-ante and ex-post evaluation of development policies such as promotion of $\mathrm{R} \& \mathrm{D}$ activities, human capital advancement or improved physical accessibility. The models simulate macro- and regional economic impacts while taking into account geographical effects such as regional innovation system features, agglomeration, migration and costs of transportation. The intention of the GMR research programme is to develop efficient and relatively simple model structures, which fit the generally weak quality of regional data. 
The GMR model consists of three blocks: regional productivity (Total Factor Productivity, TFP), Spatial Computable General Equilibrium (SCGE), and the macroeconomic (MACRO) model blocks. The effect of interventions (e.g. R\&D support, infrastructure, investments) on total factor productivity is determined in the TFP block, the equations of which are estimated by econometric methods. The detailed technical description of the block's structure can be found in the papers of Varga et al. $(2009,2013)$ and Varga and Törmä (2010).

Changes in the values of the main economic variables (output, employment, prices) induced by the effects of changing TFP are determined in the SCGE model block for each region. Thus, the aim of the model block is to evaluate the economic impacts of different economic policy interventions at the regional level. In the short term, equilibrium demand and supply for products and factors are equal to each other; however, wages might differ among regions. Wage differences might induce migration from lower wage regions; ultimately, wages impacted by migration are equalized among regions. Thus, not only each region but also the whole spatial system reaches equilibrium.

The SCGE model block takes into consideration those geographical impacts that reinforce centripetal forces, that is, spatial concentration through the change of regional productivity. In addition, the impacts mitigating centrifugal effects such as increasing congestion and costs of transportation. Regions are connected by interregional trade and migration of capital and labour. The SCGE block is a static one, the dynamism of the system is ensured by the TFP model and the macroeconomic block.

The macroeconomic block of the GMR-Europe model includes QUEST III (Ratto et al. 2009), a dynamic stochastic general equilibrium (DSGE) model developed by the European Commission. MATLAB software is used to jointly run the TFP, the SCGE and the MACRO model blocks.

The present investigation is the first use of the GMR system for a particular case when external shocks enter the model in the form of a special environmental innovation. To be able to estimate regional and macro-level effects of Blue Economy innovations, we restructured the CGE model of one region (the Hungarian Southern Transdanubian region) in the GMR-Europe model in order to make it suitable for our investigation. Since this transformation affects the SCGE block, the next subsection focuses primarily on this block.

\section{Extension: The structure of the GMR-Europe BLUE model}

The GMR-Europe model analyses the spatial effects of various economic policy interventions within a mutually connected (by means of interregional trade, geographic and knowledge network spillovers, migration of labour and capital) regional model system of 144 European regions. The present investigation transforms a selected region of this complex system to make it suitable for the modelling of Blue Economy innovations. Regional models belonging to the SCGE block of the GMR-Europe model are one-sector models that consider one aggregate product: regional GDP. However, the evaluation of the impacts of Blue Economy innovations requires a multi-sector approach. Thus, we extended one region (in the particular example the Southern Transdanubian region) of the SCGE model block into a multi-sector one. This multi-sectoral extended regional model is called the "BLUE" regional model hereinafter. 
Besides the above-mentioned change in the GMR-Europe model, many special amendments were also needed in the structure of the sectorally divided regional model to make it suitable for the analysis of Blue Economy-type innovations. Special attention was devoted to the transformed role of waste, since, after the introduction of a Blue Economy innovation, waste works as a production input, thus creates value. Besides this, it is important to emphasize that waste is a by-product, which means that the production of good(s) and the supply of its recyclable waste are not independent. The rest of this subsection discusses the alterations we made in the GMR-Europe model in detail.

Firms

The waste management sector plays an outstanding role in the multi-sector model, since the quantity of waste to be processed mainly depends on the amount of waste recycled owing to the introduction of the innovation. Thus, there are $m$ sectors differentiated in the model, $n$ of which behave similarly, while the waste processing sector is signed with a separate index, $w$.

In their production, companies use two primary resources (capital and labour) and respectively intermediate products produced by other sectors. Primary resources are assumed to be perfectly mobile among the sectors, thus having the same price in each sector. Value added is produced with primary resources following a Cobb-Douglas technology, while the use of intermediate factors is characterized by a Leontief technology. Every company emits waste during production that is transported and processed by the specialized waste management sector. Waste generated can be separated into two parts: a recyclable one that can be sold as a raw material according to the new Blue Economy technology, and a non-recyclable part. The non-recyclable share of waste is linearly proportional to the output of the company. The company's demand for waste processing equals to $a_{w i}$ of each unit of production. On the other hand, the share of potentially recyclable waste that is actually treated as a waste $\left(R U W W_{i}\right)$ varies as it depends on the reutilized quantity of the total recyclable waste produced. Thus the production function of firms has the following form:



where $x_{i}$ is the gross output of firms belonging to sector $i, X_{j i}$ is the quantity of product produced by sector $j$ and used in sector $i$, and $R U W W_{i}$ represents the quantity of waste transported and potentially reused. $r u w w_{i}$ shows the quantity of by-products dispatched as waste. However, contrary to the demand of ordinary raw materials this is not constant, but variable. Owing to the introduction of Blue Economy innovations, companies can use an additional raw material besides the products of other sectors: recyclable waste. $R U W D_{i}$ shows the quantity of recycled waste used in sector $i$, while $\tau_{i}$ represents the demand for recycled waste per unit of output in sector $i . L_{i}$ and $K_{i}$ signal the quantity of labour and capital used in the sector, $\alpha_{i}$ and $A_{i}$ are parameters of the Cobb-Douglas production function, while $b_{i}$ is the value added per unit of gross output.

The demand functions of companies for capital and labour are the following:

$$
K_{i}=\left(\frac{\left(1-\alpha_{i}\right)}{\alpha_{i}} \cdot \frac{w}{r}\right)^{\alpha_{i}} \cdot \frac{x_{i}}{A_{i}}
$$




$$
L_{i}=\left(\frac{\alpha_{i}}{\left(1-\alpha_{i}\right)} \cdot \frac{w}{r}\right)^{1-\alpha_{i}} \cdot \frac{x_{i}}{A_{i}},
$$

where $\mathrm{w}$ is the wage rate, $\mathrm{r}$ is interest on capital, while the other notations follow the abovedescribed interpretation. During the production of their main products, companies also create by-products that can potentially be used as raw materials after the introduction of the innovation. We assume that the quantity of recyclable waste generated is linearly proportional to the output, thus:

$$
R U W T_{i}=\rho_{i} \cdot x_{i},
$$

where $R U W T_{i}$ stands for the total quantity of recyclable waste produced, while $\rho_{i}$ is recyclable waste per unit of output.

Blue Economy innovations make it possible for firms to utilize by-products (previously being treated as waste) as raw materials. The demand for recyclable waste is described by the following function:

$$
R U W D_{i}=\tau_{i} \cdot x_{i}
$$

We assume that companies producing by-products agree to provide recyclable waste for free because they no longer have to bear the costs of transporting and processing of waste anymore. Thus, the quantity of a by-product utilized equals to the demand of those companies utilizing it as raw material. The demand is proportionally distributed among the sectors. Consequently, the quantity of recyclable waste that can be used as raw material is supplied by sector $i$ according to the following:

$$
R U W S_{i}=\frac{\sum_{j} R U W D_{j}}{\sum_{j} R U W T_{j}} \cdot R U W T_{i}
$$

where $R U W S_{i}$ shows how much is offered for recycling from the total by-product by company $i$. The remaining recyclable waste must be processed by the waste management sector. Its value cannot be negative, thus the maximum amount that a company can offer as waste for recycling is what it has produced.

$$
R U W W_{i}=R U W T_{i}-R U W S_{i} \geq 0
$$

The quantity of the by-product transported as waste per unit of output can be calculated by the following ratio:

$$
r u w w_{i}=\frac{R U w w_{i}}{x_{i}}
$$

Assuming perfect competition, the zero profit condition must be met in the case of each company, thus

$$
p_{i} \cdot x_{i}=\sum_{j}^{m} p_{j} a_{j i} x_{i}+p_{w} \cdot R U W W_{i}+w \cdot L_{i}+r \cdot K_{i},
$$

where $p_{i}$ stands for the price of the product of sector $i$, while $w$ and $\mathrm{r}$ represent the price of labour and capital.

Households

Consumer behaviour is modelled by a representative household. Households consume the products of all sectors and their utility is described by the following utility function

$$
U=\prod_{i=1}^{m} C_{i}^{\alpha_{H i}}
$$

where $C_{i}$ is the consumption of the household from product $i$, and $\alpha_{H i}$ is the parameter of the Cobb-Douglas utility function. 
The household spends its entire income on buying consumption goods, thus

$$
Y=\sum_{i=1}^{m} p_{i} \cdot C_{i},
$$

where $Y$ represents the income of the household.

The utility maximizing demand function of the household is the following:

$$
C_{i}=\frac{\alpha_{H i} Y}{p_{i}}
$$

The primary resources are owned by the households thus their income equals to the products of the prices and supplied quantities of primary resources.

$$
Y=w \cdot L_{S}+r \cdot K_{S}
$$

where $L_{S}$ and $K_{S}$ represent the supply of labour and capital.

\section{Market equilibrium conditions}

In case of equilibrium on the labour and capital markets factor, demand of companies equals to the supply of households, thus

$$
\begin{aligned}
& \sum_{i}^{m} L_{i}=L_{S}, \\
& \sum_{i}^{m} K_{i}=K_{S},
\end{aligned}
$$

The households' supply of labour and capital is exogenously given in a particular period, but it can change in the long run owing to interregional migration.

Equilibrium of product markets necessitates that gross production equals to the demand by companies and households. In case of the traditionally behaving $n$ sector this can be described as follows:

$$
x_{i}=\sum_{j=1}^{m} a_{j i} x_{i}+C_{i} \quad \text { if } i \neq w
$$

In case of the waste management sector, $(12 a)$ is complemented by a further element that represents the quantity of recyclable waste thrown out as waste.

$$
x_{w}=\sum_{j=1}^{m} a_{j w} x_{w}+\sum_{j}^{n} R U W W_{j}+C_{w} \quad \text { if } i=w
$$

The model includes a total of $9 m+3$ equations and $9 m+3$ vairables, but these equations are not independent, since one of the equations can be expressed by using the others, so it can be dropped. To get a regular system of equations again, we fix the price of one of the resources that of capital and this fills in the role of the numeraire.

\section{Impact mechanisms in the extended GMR-Europe model}

In accordance with the logic of the SCGE model block, we search for the regionally different factor prices (ws, and rs) that ensure the equilibrium of demand and supply for factors at the regional level. The same holds for the Southern Transdanubian region, however, the demand for labour and capital is not aggregately determined since the sectorally disaggregated BLUE model comes into action in case of this single region. Thus, the SCGE model block includes aggregate Southern Transdanubia, while the BLUE model block provides its sectoral details and the current values of variables are corresponded to each other one by one. The details can be studied in Figure 1.

Since the factor prices are sectorally identical, the value of $w$ is the same in the BLUE model as in the aggregate Southern Transdanubian segment of the SCGE model. The same holds for $\mathrm{r}$. Both model blocks can be calculated by optionally choosing $\mathrm{w}$ and $\mathrm{r}$, but most 
likely, this does not initially lead to equilibrium on the factor markets. Thus, we search for factor prices at which the demand for labour equals to its supply $\left(\mathrm{L}_{\mathrm{dem}}=\mathrm{L}_{\mathrm{s}}\right)$ and the demand for capital equals to capital supply $\left(\mathrm{K}_{\mathrm{dem}}=\mathrm{K}_{\mathrm{s}}\right)$. Factor demands are sectorally $\left(\mathrm{L}_{\mathrm{dem} \text {,sec }}\right.$ and $\mathrm{K}_{\mathrm{dem}, \mathrm{sec}}$ ) calculated in the BLUE model, and they are influenced not only by prices, but also by the sectoral value added figures based on sectoral outputs $\left(\mathrm{X}_{\mathrm{sec}}\right)$. Additionally, sectoral product prices $\left(\mathrm{P}_{\mathrm{sec}}\right)$ are also influenced by the factor prices.

The BLUE model in a one-sector environment



Source: own compilation.

The sectoral structure of prices and value added evolving in the BLUE model determines the aggregate "f.o.b." (excluding transportation costs) product price of the region through which Southern Transdanubia participates in interregional trade. By adding transportation costs, we get the "c.i.f" (p) price by which Southern Transdanubia competes on the different regional markets including its domestic market. Through modelling interregional trade, we get the aggregate demand $\left(\mathrm{C}_{\text {interreg }}\right)$ for the products of each region, including Southern Transdanubia. However, in case of this region, aggregate demand is also sectorally determined within the BLUE model block $\left(\mathrm{C}_{\mathrm{sec}}\right)$. Sectoral input-output relationships establish the connection between sectoral demand for final products of Southern Transdanubia and sectoral outputs. At this point we close the circle in Figure 1, thus, at any pairs of factor prices $(\mathrm{w}, \mathrm{r}$ ) and sectoral outputs, the sum of sectoral factor demands provides the aggregate factor demands of the region. In case of the "proper" choice of factor prices, factor demands must be equal to factor supplies. These equilibrium factor prices are determined by an algorithm, which is followed in solving the system of 
equations assuming constant factor supply in the short run. This is why we call this solution the short run equilibrium that applies for one period of time. The results are substituted into the utility function $(\mathrm{U})$ of the SCGE model block that helps to calculate labour force migration; ultimately, the supply of labour $\left(\mathrm{L}_{\mathrm{s}}\right)$ will also change.

Figure 2 shows how the different parts of the model are connected. Our intervention goes through the different blocks of the GMR model as follows. In the first step, the new input-output table representing a Blue Economy innovation is inserted into the regional SCGE model. At the same time, the original, unmodified TFP values from the TFP block are also inputted. Following the modified input-output tables, the quantity of capital, labour and production, wages, interest on capital and the prices of products are calculated for each region and each time period.

Figure 2

Impact mechanisms of Blue Economy innovations in the GMR-Europe model

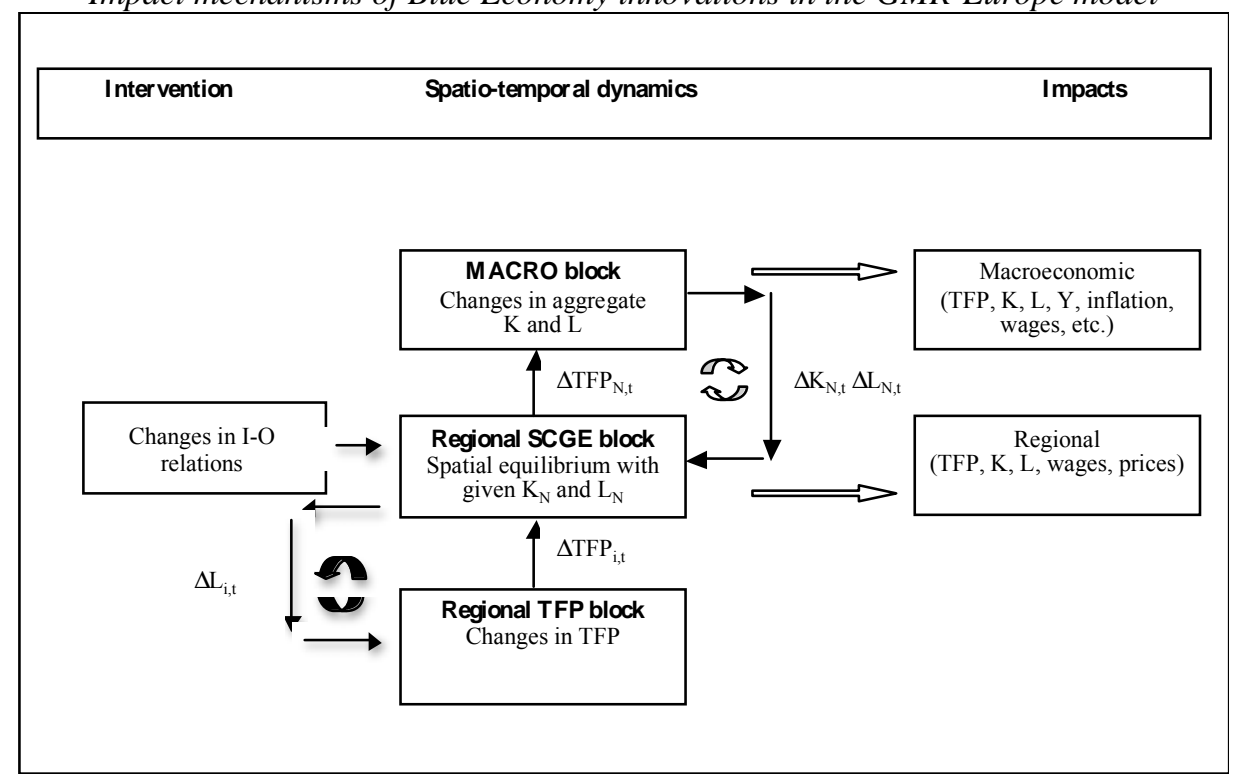

Source: own compilation.

Differences in the utility among the regions induce labour migration and capital flows, which cause a change in the TFP of the regions. In the third step, the new regional TFP values are calculated and inserted in the macro block. Finally, owing to the effect of the new TFP values, current values of the macro variables are determined for every period. In the fourth step, the changes of capital and labour calculated in the macro block will be distributed among the regions based on the pattern of regional TFP changes generated by the intervention for each period. In the fifth step, the SCGE model block runs again with the modified quantities of capital and labour and the new quantities and prices will be calculated for each region and each time period.

Thus, we compare the impacts on certain macroeconomic and regional variables (such as output, employment, investment, prices, etc.) calculated with the new I-O table 
representing a Blue Economy innovation (the "scenario") with variables calculated without this innovation (the "baseline"). Differences in the values of the variables between the baseline and the scenario are considered as the impacts of the introduction of an innovation. The following section shows how we applied the model system for simulating the likely effects of a blue economy innovation introduced in the Southern Transdanubian region.

\section{A Blue Economy innovation: growing mushroom on coffee grounds. Data and results}

The innovation we choose from the examples in Pauli (2010) is relevant for the Southern Transdanubian region, and its impacts are technically treatable within the GMR-model system. This led to the selection of the technology of growing mushroom on coffee grounds. Mushroom growing in the Southern Transdanubian region (especially in the area of Pécs) can be considered as significant (711 tons in 2009, dominantly champignon). The merit of the selected Blue Economy innovation is that, contrary to traditional technologies of mushroom growing, it uses coffee grounds, which remain after brewing coffee as a substratum. This process requires significantly less input (chemical, sterilization, energy), since the coffee grounds are already sterile after brewing. Thus there is no need for further processes. Additionally, the material (the coffee grounds), which is usually deposited as waste can serve as a production input.

Our study analyses the likely impacts of a complete shift in the technology of mushroom growing from the current one to a form where the entire mushroom growing process is based on coffee grounds. This study only accounts for the impact of coffee grounds collected from catering sites. Restaurants and coffee bars already store coffee grounds separately (for operational reasons); thus we can assume that they are willing to give it free to a potential mushroom grower. Besides this, collection of coffee grounds does not induce extra costs on restaurants; additionally, they can make savings by paying less to the waste-processing sector. Nevertheless, collection of coffee grounds entails significant transportation costs that must be considered among the costs of mushroom growing. Technical details on I-O table regionalization and deriving the data on mushroom growing technology are provided in the Appendix. Since the sector analysed (mushroom growing) only represents a small proportion of the total production of the Southern Transdanubian region, aggregate results at the regional level are expected to be minor only. Let us first analyse the change in output in the first year. These impacts are shown in Table A2.

The most striking result is the increase in the output of the mushroom producing sector by 11 percent. This rise is down to the decreased costs of mushroom production because one of the inputs (coffee grounds) is now freely available for producers. Resulting from the decline in costs, companies can supply mushroom for a lower price, which in turn increases the quantity demanded. A further expected result is the shrinking of the wasteprocessing sector, even if only on a small scale. As there will be less coffee-ground waste. On the other hand, the output of the sector that includes transportation ("Wholesale and retail trade, repair of motor vehicles and motorcycles, Transportation and storage, Accommodation and food service activities") increased. This is because coffee-ground has to be collected from multiple sites and in relatively small portions, which increase transportation need. A further interesting result is the increase in electricity required due 
to both direct and indirect effects. The direct effect is the relatively high demand of the mushroom growing sector for electricity, since appropriate humidity and temperature play a significant role in mushroom growing. Thus, increased mushroom production requires increased electricity production and air conditioning. Furthermore, it can be assumed that higher transportation need also increases the demand for energy.

Output of the agricultural sector slightly decreased because of the substitution of the raw material that stemmed earlier from this sector (compost) by coffee-ground. It is also worth mentioning that the output of chemicals also decreased, because of the use of the already sterile coffee grounds. Application of this input thus does not require further treatment of the substratum in mushroom growing.

\section{Summary}

Our study introduced a model framework that is applicable to the impact assessment of particular kinds of environmental innovations called Blue Economy innovations. The main novelty of these technologies is that they use certain products, which are usually considered waste, as production inputs. These innovations reduce the production of waste on the one hand and diminish the raw material needs of the economy on the other. To be able to analyse the effects of such innovations, we used a multi-sector general equilibrium model that can reveal the transformed relationships among economic sectors. Due to relatively high transportation costs, these innovations rely much on spatial proximity of firms, which should also be incorporated into the structure of impact models. To account for the role of geography in our analysis, we applied the GMR-Europe model. The SCGE block of the GMR-Europe model was developed in a way that it became suitable for the impact assessment of these innovations. Finally, we illustrated the capabilities of the model with a specific example. We analysed the effects arising from the use of coffee grounds as a substratum in mushroom production (a Blue Economy innovation) and compared them to those of a widely used current technology. The empirical analysis was run for data of the Hungarian South Transdanubian Region. Due to the small share of the mushroom growing sector in the regional economy, the effects found are quite small. Even against this, we experienced visible impacts, primarily owing to changes in intersectoral relations.

\section{REFERENCES}

Barata, E. (2002): Solid waste generation and management in Portugal: An environmental input-output modeling approach Paper prepared for the 7th Biennial Conference of the International Society for Ecological Economics, "Environment and Development: Globalisation \& the Challenges for Local \& International Governance", 6-9 March 2002, Sousse (Tunisia).

Baumgärtner, S. (2004): Price ambivalence of secondary resources: joint production, limits to substitution, and costly disposal Resources, Conservation and Recycling 43 (1): 95-117.

Bonfiglio, A. (2005): A Sensitivity Analysis of the Impact of CAP Reform. Alternative Methods of Constructing Regional Input-Output Tables Ph.D. Studies, No. 1., Ancona, Italy.

Flegg, A.-Thomo, T. (2013): Regional Input-Output Tables and the FLQ Formula: A Case Study of Finland Regional Studies 47 (5): 703-721.

Járosi P.-Koike, A.-Thissen, M.-Varga A. (2010): Regionális fejlesztéspolitikai hatáselemzés térbeli számszerüsített egyensúlyi modellel Közgazdasági Szemle 57 (2): 165-180. 
Kuhar, A.-Kuhar, A. G.-Erjave, E.-Kozar, M.-Cör, T. (2009): Regionalisation of the Social Accounting Matrix - Methodological review Common Agricultural Policy Regional Impact - The Rural Development Dimension Collaborative project - Small to medium-scale focused research project under the Seventh Framework Programme Project No.: 226195, University of Ljubljana, Ljubljana.

Miyata, Y. (1995): A General Equilibrium Analysis of the Waste-Economic System - A CGE modeling approach Infrastructure Planning Review 12: 259-270.

Pauli, G (2010): The blue economy - 10 years, 100 innovations, 100 million jobs Report to the Club of Rome, Paradigm Publications, Taos.

Ratto, M.-Roeger, W.-Veld, J. (2009): QUEST III: An estimated open-economy DSGE model of the euro area with fiscal and monetary policy Economic Modelling 26 (1): 222-233.

Speck, S. (1997): A neo-Austrian five process model with resource extraction and pollution abatement Ecological Economics 21 (2): 91-103.

Varga A.-Törmä H. (2010): The extended GMR modeling system. Study on the impact of the Single Market on Cohesion: Implications for Cohesion Policy, Growth and Competitiveness. DG Regio project, Methodology Report, European Commission, Brussels.

Varga, A.-Schalk, H.-Koike, A.-Járosi, P.-Tavasszy, L. (2008): Integrating the effects of geography into EU Cohesion Policy impact modeling: The GMR-approach Paper presented at the modeling workshop of the German Section of the European Regional Science Association, University of Kiel., Kiel.

Varga, A.-Járosi, P.-Sebestyén, T. (2009): Geographic Macro and Regional Model for EU Policy Impact Analysis of Intangible Assets and Growth Working Paper IAREG WP5/20., Barcelona.

Varga, A.-Járosi, P.-Sebestyén, T. (2013): A GMR-Európa modell és alkalmazása EU kohéziós politikai reformok előzetes hatásvizsgálata során Szigma 45 (1-2): 117-143.

Varga, A.-Pontikakis, D.-Chorafakis, G. (2014): Metropolitan Edison and cosmopolitan Pasteur? Agglomeration and interregional research network effects on European R\&D productivity Journal of Economic Geography 14 (2): 229-263.

\section{A1. Regionalizing Input-Output tables}

APPENDIX

Many technical problems had to be resolved during the impact assessment of the chosen Blue Economy innovation. With respect to the inputs, a solution must have been found on how to take into consideration and insert the technology of a previously non-existing, entirely new branch and how the starting values of the input data can be generated. Since producers will use a new technology with the implementation of the innovation, a methodology is needed that can take into consideration the change in the production technology. We used an input-output table estimated for the Southern Transdanubian region to analyse the technology of the Blue Economy innovation. The impact assessment was run within the framework of the GMR-Europe model. Since (as it has already been discussed in the previous chapter) this model includes only one aggregated sector, it is not able to take into consideration the interconnections of different industrial sectors. Thus for the analysis we extended the SCGE model block in a way that we were able to track intersectoral effects of the innovation.

The estimated regional input-output table served as the base for the simulations. A physical input-output table would be an excellent instrument for the impact assessment. However, for Hungary, the table of intersectoral connections expressed in physical units is not available, so we used the traditional monetary table of intersectoral relations. A further problem is that the Hungarian Central Statistical Office (HCSO) compiles only national 
I-O tables, thus first we had to estimate it for the Southern Transdanubian region to be able to analyse the effects of the innovation.

There is a broad literature on the regionalization of input-output tables (Kuhar et al. 2009). The three types of methods that have been most widely applied are the survey, nonsurvey and hybrid methods (Bonfiglio 2005). When survey methods are followed, companies in the region are asked to provide production data and then the table will be compiled based on the data received. A distinct advantage of this method is that it can detect input-output relations with a good estimate. However, the disadvantage is that the determination of those is a very costly process. Non-survey methods can be used if there is no data available on input-output connections in the region; consequently, the whole table must be estimated. These methods require only a few data and are relatively easy to carry out. Additionally, they are not so costly compared to the survey methods. However, their disadvantage is that they cannot provide precise results. The hybrid methods are meant to unify the advantages of the previous two groups, namely appropriate precision and relatively low costs. This requires the availability of preliminary (survey) data on regional input-output connections. Usually, the most important and largest branches of the region are mapped with a survey and after that, the remaining parts of the table are estimated by a non-survey method. Since no survey data are available for Southern Transdanubia, we used a non-survey method to carry out the estimation. The regionalization of the table followed a two-step process. First, by using the LQ-method, we adjusted the cells of the coefficient matrix to regional production specificities, and determined the scale of interregional export and import; then we ensured the fit to the regional data by using the RAS method. More technical details on these techniques can be found e.g. in Bonfiglio (2005) and Flegg and Thomo (2013).

\section{A2. Deriving data on mushroom growing technology}

Since mushroom growing is part of agriculture in the HSCO tables, we decided to separate the mushroom growing sector from agriculture. Consequently, we established a new inputoutput table that included mushroom growing as a new sector additional to agriculture excluding mushroom production. Of course, there is no overlap between these two sectors. During the model runs, this table was inserted into the SCGE block. We consider the results attained with this table as the baseline scenario.

The alternative scenario includes the effects of the Blue Economy innovation. The starting point was the regional input-output table estimated previously. However, during the analysis we assumed that the whole mushroom growing industry of the region uses the new technology thus the whole branch shifts to the new production method. Consequently, the impact assessment will show the results expected if the Blue Economy innovation is applied in the entire mushroom growing sector. We assumed that the entire amount of coffee grounds that can potentially be collected from catering places were used by the mushroom growing sector. The output of the sector was calculated then by assuming the application of the new technology. After estimating the output and inputs required, data of the mushroom growing sector with the old technology was replaced by the data estimated with the new technology in the input-output table. Then the model was run again using the new table. 
Technological coefficients in case of traditional and Blue Economy types of mushroom growing

\begin{tabular}{l|c|c}
\hline & \multicolumn{2}{|c}{ I-O coefficients } \\
\cline { 2 - 3 } \multicolumn{1}{c|}{ Sector } & traditional & $\begin{array}{c}\text { Blue } \\
\text { type }\end{array}$ \\
\hline Agriculture, forestry, fishing & 0.200 & 0.056 \\
Mining and quarrying & 0.054 & 0.000 \\
Manufacture of food products, beverages and tobacco products & 0.000 & 0.000 \\
Manufacture of textiles, wearing apparel, leather and related products & 0.000 & 0.000 \\
Manufacture of wood and paper products, and printing & 0.000 & 0.000 \\
Manufacture of chemicals and chemical products, Manufacture of pharmaceuticals, & & \\
manufacture of coke & 0.019 & 0.000 \\
Manufacture of rubber and plastics products, and other non-metallic mineral products & 0.111 & 0.046 \\
Manufacture of basic metals and fabricated metal products, except machinery and & & \\
equipment & 0.000 & 0.000 \\
Machinery & 0.000 & 0.000 \\
Other manufacturing and repair and installation of machinery and equipment & 0.000 & 0.000 \\
Electricity, gas, steam and air conditioning supply & 0.073 & 0.118 \\
Water supply & 0.001 & 0.001 \\
Construction & 0.000 & 0.000 \\
Wholesale and retail trade, repair of motor vehicles and motorcycles, & & \\
Transportation and storage, Accommodation and food service activities & 0.000 & 0.099 \\
Information and communication & 0.000 & 0.000 \\
Financial and insurance activities & 0.000 & 0.000 \\
Real estate activities & 0.000 & 0.000 \\
Professional, scientific and technical activities, Administrative and support service & & \\
activities & 0.000 & 0.000 \\
Public administration and defence; compulsory social security, Education, Human & & 0.000 \\
health and social work activities & 0.000 & 0.000 \\
Arts, entertainment and recreation, Other services, Other activities & 0.000 & 0.000 \\
Mushroom & 0.000 & 0.000 \\
Sewage, waste management and remediation activities &
\end{tabular}

The technological coefficients of the two types of mushroom growing can be found in Table A1. The differences are rooted in the differences between the two technologies. For example, traditional mushroom growing has a higher agricultural coefficient, since, besides mushroom spawn it also uses compost. Additionally, the Blue Economy Innovation does not use any output of the mining industry, while the traditional production does (sand and peat). It can also be seen that only the traditional method of growing requires the use of chemicals, however, raising the crop on coffee grounds has a larger energy demand (especially due to lightning). Water consumption is not significantly different and approximately equal in both cases. Resulting from the need of transporting coffee grounds, the Blue Innovation also uses the trading sector as an input. In restaurants of the Southern Transdanubian region, approximately 214,000 tons of coffee grounds are produced annually that can potentially be used for mushroom growing. 
Expected sectoral impacts of the implementation of Blue Economy-type mushroom growing

\begin{tabular}{|c|c|c|c|}
\hline \multirow{2}{*}{ Sector } & \multicolumn{3}{|c|}{ Gross output $(\mathrm{X})$} \\
\hline & baseline & scenario & change, $\%$ \\
\hline Agriculture, forestry, fishing & 549.076 & 548.929 & -0.0267 \\
\hline Mining and quarrying & 12.154 & 12.108 & -0.3773 \\
\hline $\begin{array}{l}\text { Manufacture of food products, beverages and tobacco } \\
\text { products }\end{array}$ & 153.324 & 153.323 & -0.0004 \\
\hline $\begin{array}{l}\text { Manufacture of textiles, wearing apparel, leather and related } \\
\text { products }\end{array}$ & 50.710 & 50.709 & -0.0015 \\
\hline Manufacture of wood and paper products and printing & 24.839 & 24.839 & -0.0005 \\
\hline $\begin{array}{l}\text { Manufacture of chemicals and chemical products, } \\
\text { Manufacture of pharmaceuticals, } \\
\text { manufacture of coke }\end{array}$ & 252.638 & 252.610 & -0.0111 \\
\hline $\begin{array}{l}\text { Manufacture of rubber and plastics products and } \\
\text { other non-metallic mineral products }\end{array}$ & 64.321 & 64.295 & -0.0409 \\
\hline $\begin{array}{l}\text { Manufacture of basic metals and fabricated metal products, } \\
\text { except machinery and equipment }\end{array}$ & 66.936 & 66.935 & -0.0019 \\
\hline Machinery & 184.489 & 184.490 & 0.0001 \\
\hline $\begin{array}{l}\text { Other manufacturing and repair and installation of } \\
\text { machinery and equipment }\end{array}$ & 4.821 & 4.821 & -0.0001 \\
\hline Electricity, gas, steam and air conditioning supply & 223.899 & 223.947 & 0.0213 \\
\hline Water supply & 7.800 & 7.800 & -0.0049 \\
\hline Construction & 414.626 & 414.628 & 0.0004 \\
\hline $\begin{array}{l}\text { Wholesale and retail trade, repair of motor vehicles and } \\
\text { motorcycles, Transportation and storage, Accommodation } \\
\text { and food service activities }\end{array}$ & 1054.307 & 1054.390 & 0.0079 \\
\hline Information and communication & 133.623 & 133.624 & 0.0008 \\
\hline Financial and insurance activities & 151.926 & 151.927 & 0.0005 \\
\hline Real estate activities & 449.392 & 449.401 & 0.0019 \\
\hline $\begin{array}{l}\text { Professional, scientific and technical activities, } \\
\text { Administrative and support service activities }\end{array}$ & 288.944 & 288.947 & 0.0011 \\
\hline $\begin{array}{l}\text { Public administration and defence; compulsory social } \\
\text { security, Education, Human health and social work activities }\end{array}$ & 1250.779 & 1250.770 & -0.0007 \\
\hline $\begin{array}{l}\text { Arts, entertainment and recreation, Other services, } \\
\text { Other activities }\end{array}$ & 181.508 & 181.508 & 0.0004 \\
\hline Mushroom & 0.738 & 0.817 & 10.8212 \\
\hline Sewage, waste management and remediation activities & 21.148 & 21.148 & -0.0026 \\
\hline
\end{tabular}

